\title{
Anatomical variations of median nerve formation, distribution and possible communication with other nerves in preserved human cadavers
}

\author{
C.N. Mat Taib1 ${ }^{1}$, S.N.A. Hassan², N. Esa², M.A. Mohd Moklas¹, A.A. San ${ }^{3}$ \\ ${ }^{1}$ Department of Human Anatomy, Faculty of Medicine and Health Sciences, Universiti Putra Malaysia, \\ Selangor, Malaysia \\ ${ }^{2}$ Faculty of Medicine and Health Sciences, Universiti Putra Malaysia, Selangor, Malaysia \\ ${ }^{3}$ Faculty of Medicine and Health Sciences, USCI, Malaysia
}

[Received: 16 June 2016; Accepted: 18 July 2016]

Formation, distribution and possible communication of the median nerve are essential to know in treatment and surgeries of various conditions of injuries e.g. repair or reconstruction of the median nerve post traumatic accident. In the present study, 44 upper limbs were dissected. Root forming the median nerve, the median nerve in relation with the axillary artery and communication of the median nerve with other nerves were noted. (Folia Morphl, 2017; 76, 1: 38-43)

Key words: axillary artery, brachial plexus, median nerves, musculocutaneous nerve, ulnar nerve, medial root, lateral root

\section{INTRODUCTION}

The median nerve is the union of lateral root and medial root of lateral cord $(\mathrm{C} 5, \mathrm{C} 6)$ and medial cord $(\mathrm{C} 8, \mathrm{~T} 1)$ of the brachial plexus respectively $[1,9,11,15]$. Knowledge on the median nerve variations is very important especially for anaesthesiologists and surgeons who deal with surgery around axilla and upper arm so that they can prevent post-operative complications. Therefore, a study about anatomical variations of the median nerve among cadavers was done.

\section{MATERIALS AND METHODS}

Forty-four upper limbs from 22 formalin-preserved cadavers from the Faculty of Medicine and Health Sciences UPM were dissected according to Cunningham's Manual of Practical Anatomy [16] after receiving ethical clearance from the ethics committee of JKEUPM (ref no: FPSK(EXP15-medic)u16). All variations in formation and distribution of the median nerve and its communication with other nerves were photographed and calculated. McNemar test was done to study the comparison of the median nerve variations with the side of upper limb.

\section{RESULTS}

Table 1 shows the distribution of variations of the median nerve. Normal formation of the median nerve from two roots represented $63.6 \%$ (14) and $72.7 \%$ (16) for the left and right upper limb, respectively. Another three variations of median nerve formation: by one root, three roots and four roots were also observed. Three roots forming the median nerve were found in about $36.4 \%$ (8) in left upper limb and $18.2 \%$ (4) in right one (Fig. 1). More variations were observed in the right upper limb. The median nerve formed from one root (Fig. 2) and four roots (Fig. 3) gave $4.5 \%$ each. Normal course of the median nerve in relation to the axillary artery have the same 
Table 1. Distribution of anatomical variations of the median nerve

\begin{tabular}{lcc}
\hline $\begin{array}{l}\text { Anatomical variation } \\
\text { of median nerve }\end{array}$ & \multicolumn{2}{c}{$\begin{array}{c}\text { Number } \\
\text { of specimens (n = 44) }\end{array}$} \\
\cline { 2 - 3 } & Left (\%) & Right (\%) \\
\hline Number of roots forming median nerve: & \\
1 root & $0(0 \%)$ & $1(4.5 \%)$ \\
2 roots (normal) & $14(63.6 \%)$ & $16(72.7 \%)$ \\
3 roots & $8(36.4 \%)$ & $4(18.2 \%)$ \\
4 roots & $0(0 \%)$ & $1(4.5 \%)$ \\
Median nerve in relation to axillary artery: & \\
Anterior/lateral (normal) & $18(81.8 \%)$ & $18(81.8 \%)$ \\
Medial & $1(4.5 \%)$ & $3(13.6 \%)$ \\
Posterior & $3(13.6 \%)$ & $1(4.5 \%)$ \\
Communication with other nerves: & & \\
No communication (normal) & $19(86.4 \%)$ & $21(90.9 \%)$ \\
With musculocutaneous nerve & $3(13.6 \%)$ & $0(0 \%)$ \\
With ulnar nerve & $0(0 \%)$ & $1(4.5 \%)$ \\
\hline
\end{tabular}

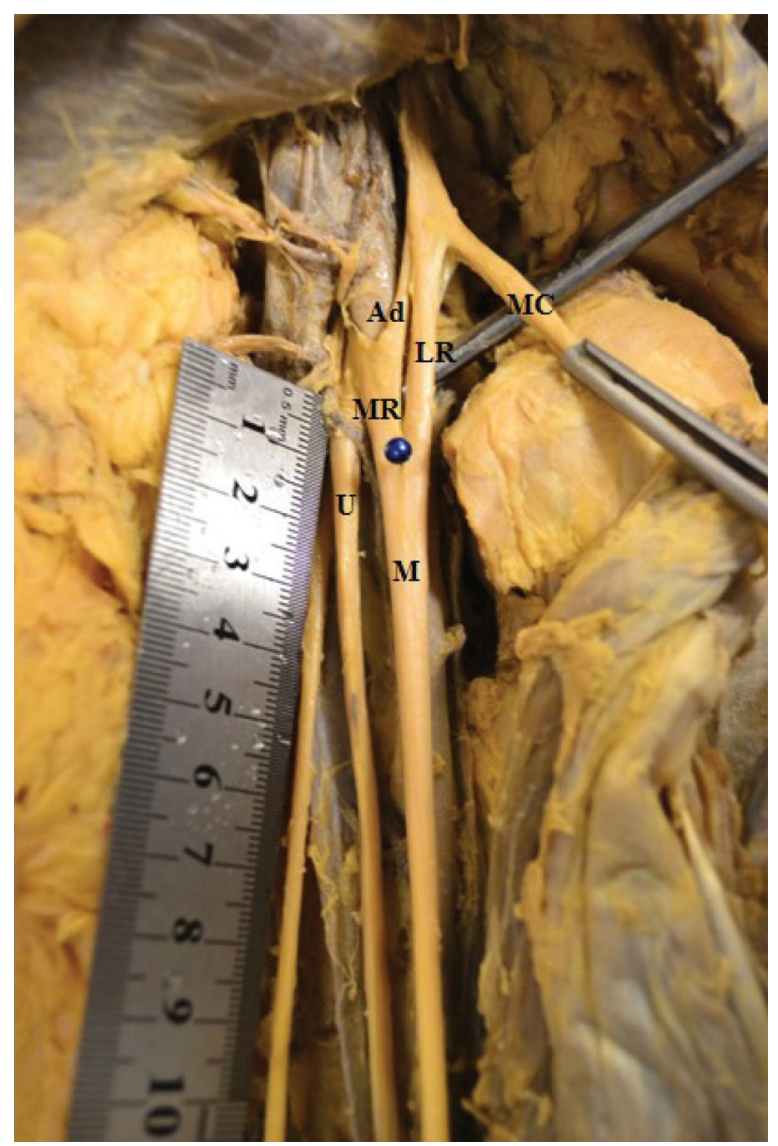

Figure 1. View of formation of the median nerve from three roots; $\mathrm{Ad}$ - additional root; LR — lateral root; $\mathrm{M}$ - median nerve; $\mathrm{MC}$ - musculocutaneous nerve; $\mathrm{MR}$ - medial root; $\mathrm{U}$ - ulnar nerve. distribution on the left and right side, $81.8 \%$ (18). In $3(13.6 \%)$ samples the median nerve was running posterior to the axillary artery and in $4.5 \%$ (1) medial to the axillary artery in the left upper limb. On the other hand, it has been shown for the right upper limb that in $13.6 \%$ (3) of samples the median nerve was running medial to the axillary artery and in $4.5 \%$ (1) posterior to axillary artery. Most of the specimens showed no communication with other nerve, $86.4 \%$ (19) and $90.9 \%$ (21) in the left and right upper limb, respectively. Three (13.6\%) samples were observed having communication with the musculocutaneous nerve (MC) in the left upper limb (Fig. 4) and only $1(4.5 \%)$ sample had communication with the ulnar nerve in the right upper limb (Fig. 5).

Table 2 shows the result from McNemar test for three different parameters in relation to the side of upper limb. Parameters studied were formation of the median nerve from the brachial plexus, course of the median nerve in relation to the axillary artery

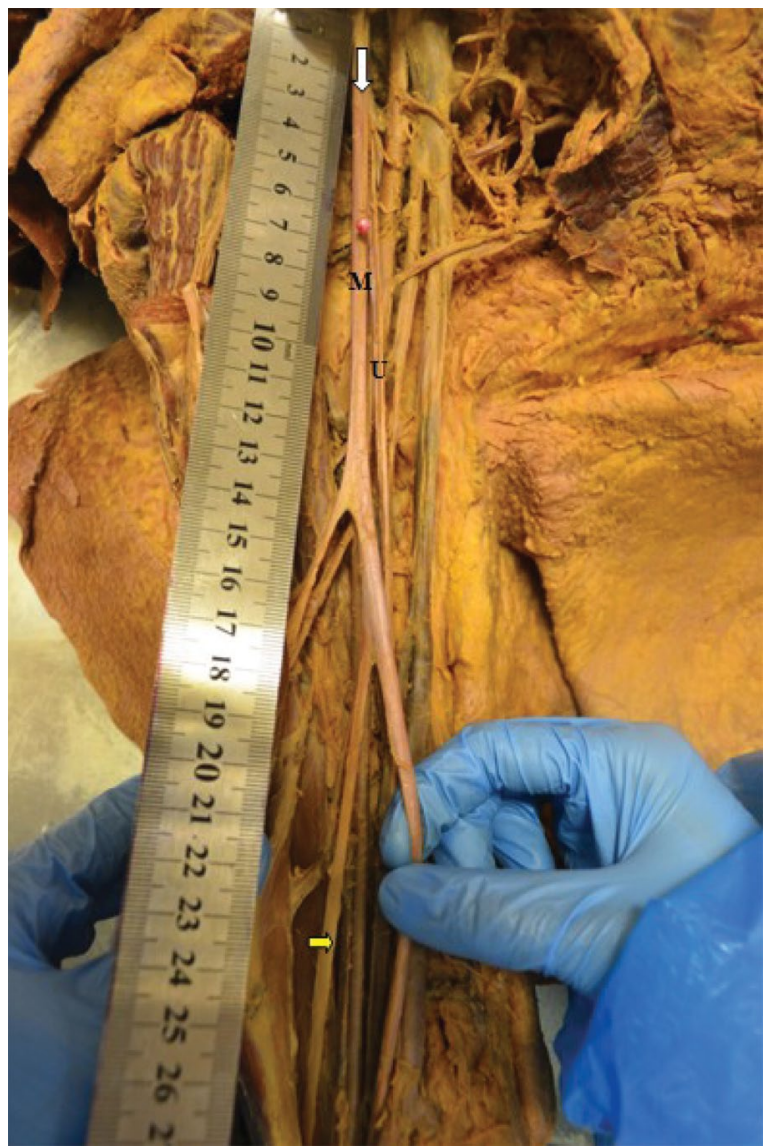

Figure 2. View of formation of the median nerve from one root. Median nerve arises directly from medial cord of the brachial plexus (white arrow). Yellow arrow shows the lateral cutaneous nerve of forearm; $\mathrm{M}$ - median nerve; $\mathrm{U}$ - ulnar nerve. 


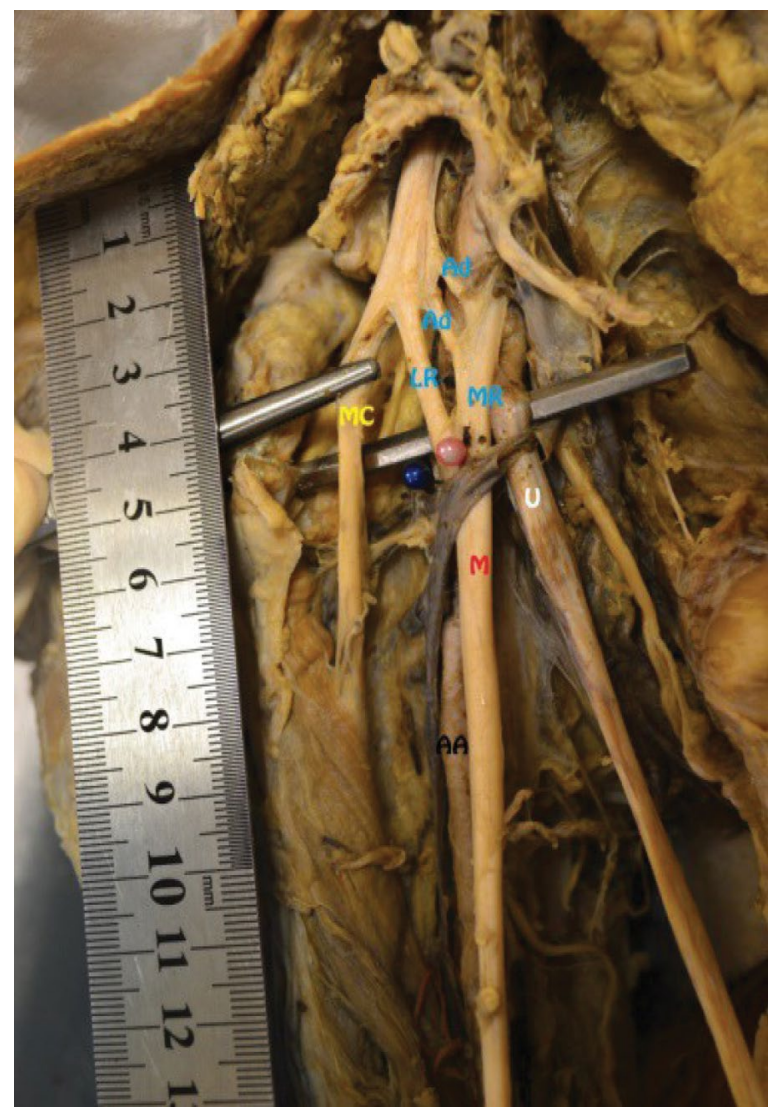

Figure 3. View of formation of the median nerve from four roots. Three roots arise from lateral cord and one root arises from medial cord; AA — axillary artery; Ad — additional root; LR — lateral root; $\mathrm{M}$ - median nerve; $\mathrm{MC}$ - musculocutaneous nerve; $\mathrm{MR}$ - medial root; U — ulnar nerve.

and communication of the median nerve with other nerves. The $p$ value obtained for each parameter was $0.754,1.000$ and 0.625 , respectively. The $p$ values were not significant, $p>0.05$ (the significance threshold was set at $p<0.05$ ). Therefore, there was no significant association between variations of the median nerve with the side of upper limb.

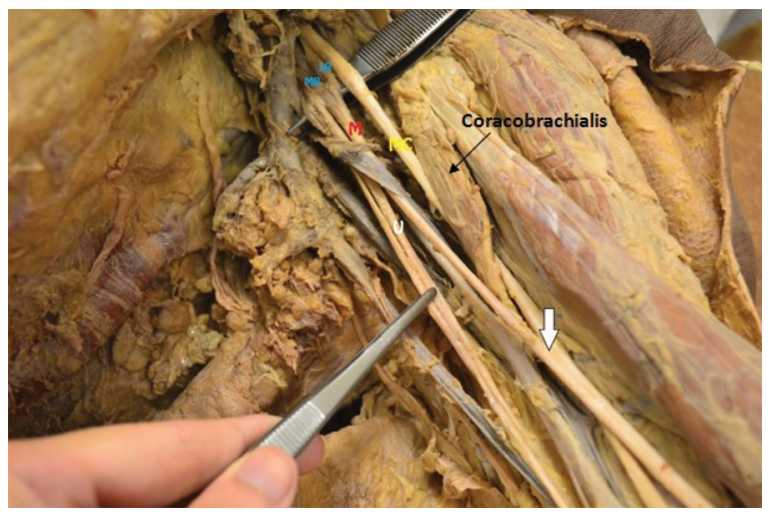

Figure 4. View of communication between the median nerve and the musculocutaneous nerve. White arrow shows the meeting point between the nerves after $\mathrm{MC}$ pierce the coracobrachialis; $\mathrm{LR}$ - lateral root; $\mathrm{M}$ - median nerve; $\mathrm{MC}$ - musculocutaneous nerve; MR — medial root.

\section{DISCUSSION}

Formation of the median nerve from the brachial plexus

In the present study, formation of the median nerve from three roots was the most frequent variation found: $36.4 \%(8 / 22)$ on the left side and $18.2 \%$ $(4 / 22)$ on the right side. In all cases with three roots, two of them were from lateral cord and one from medial cord (Fig. 3). and only 1 specimen on the right side was found to have four roots $(4.5 \%)$, among which one root was from medial cord, one root from lateral cord and 2 additional branches were from lateral cord joining medial root (Fig. 1). This is in line with the study of Budhiraja et al. [4] who found two types of variation: median nerve formed by three roots and four roots in $22.4 \%$ (44/196) and $3.57 \%$ (7/196), respectively. In our study, all additional roots arose from lateral cord.

Table 2. Comparison of anatomical variations of the median nerve between right and left upper limbs

\begin{tabular}{|c|c|c|c|c|c|}
\hline \multicolumn{2}{|c|}{ Variations of median nerve in left upper limb } & \multicolumn{2}{|c|}{$\begin{array}{l}\text { Variations of median nerve } \\
\text { in right upper limb }\end{array}$} & \multirow[t]{2}{*}{ Total } & \multirow[t]{2}{*}{$\mathbf{P}$} \\
\hline & & Absent & Present & & \\
\hline \multirow[t]{2}{*}{ Roots forming from brachial plexus } & Absent & $10(45.5 \%)$ & $4(18.2 \%)$ & $14(63.6 \%)$ & 0.754 \\
\hline & Present & $6(27.3 \%)$ & $2(9.1 \%)$ & $8(36.4 \%)$ & \\
\hline \multirow[t]{2}{*}{ Relation to axillary artery } & Absent & $14(63.6 \%)$ & $4(18.2 \%)$ & $18(81.8 \%)$ & 1.000 \\
\hline & Present & $4(18.2 \%)$ & $0(0.0 \%)$ & $4(18.2 \%)$ & \\
\hline \multirow[t]{2}{*}{ Communication with other nerves } & Absent & $18(81.8 \%)$ & $1(4.5 \%)$ & $19(86.4 \%)$ & 0.625 \\
\hline & Present & $3(13.6 \%)$ & $0(0.0 \%)$ & $3(13.6 \%)$ & \\
\hline
\end{tabular}




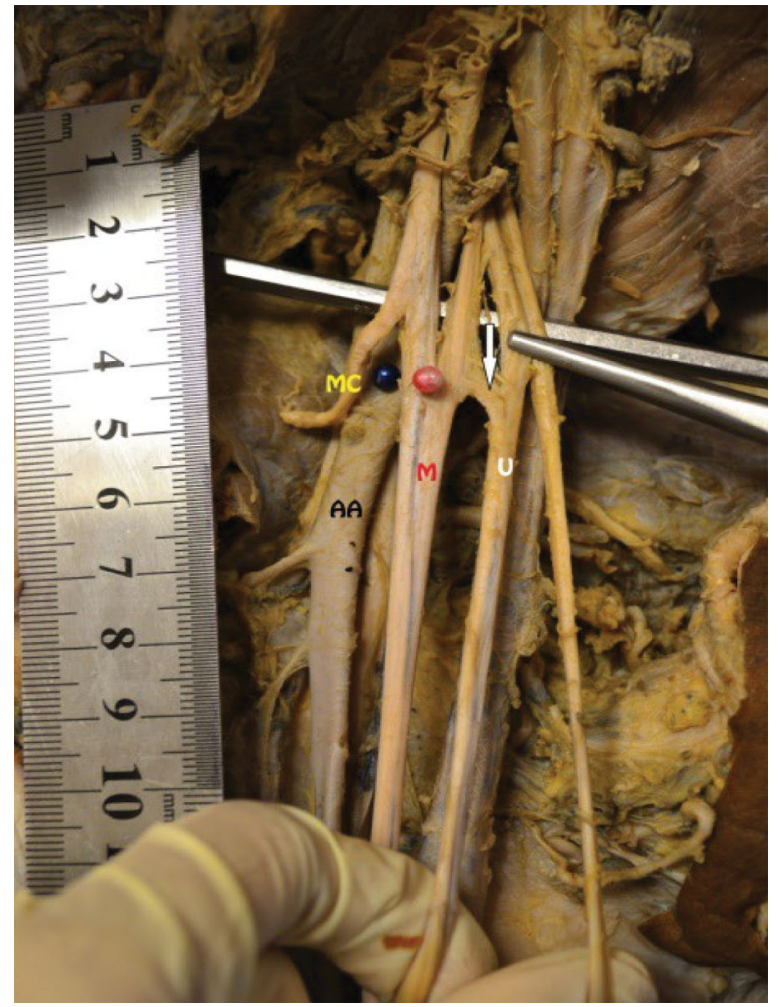

Figure 5. View of fine communication between the median nerve and the ulnar nerve as shown by white arrow. The median nerve is located medial to axillary artery; AA - axillary artery; $\mathrm{M}$ median nerve; $\mathrm{MC}$ - musculocutaneous nerve; $\mathrm{U}$ - ulnar nerve.

These findings are quite different from those of Budhiraja et al. [4] where the additional roots come either from MC in $8.16 \%$ or from lateral cord of the brachial plexus in 14.2\%. Badawoud [2] also found the same variations as our study and reported that in $2.1 \%(1 / 48)$ the median nerve was formed by 4 roots and in $6.3 \%(3 / 48)$ by three roots.

In addition, 1 male specimen was found to have unique median nerve formation: it was formed directly from the medial cord in the right upper limb (Fig. 2). In this specimen, the medial cord gave its normal branches (ulnar nerve, medial cutaneous nerve of arm, medial cutaneous nerve of forearm and medial pectoral nerve) and no MC was spotted. Therefore, the median nerve supplied all the flexor muscles of arm and gave the lateral cutaneous nerve of forearm at the lower third of arm. Unfortunately, we could not found any previous literature on this type of variation. However, it may explain the presence of weak arm flexors in patients with thoracic outlet syndrome and median nerve affection.

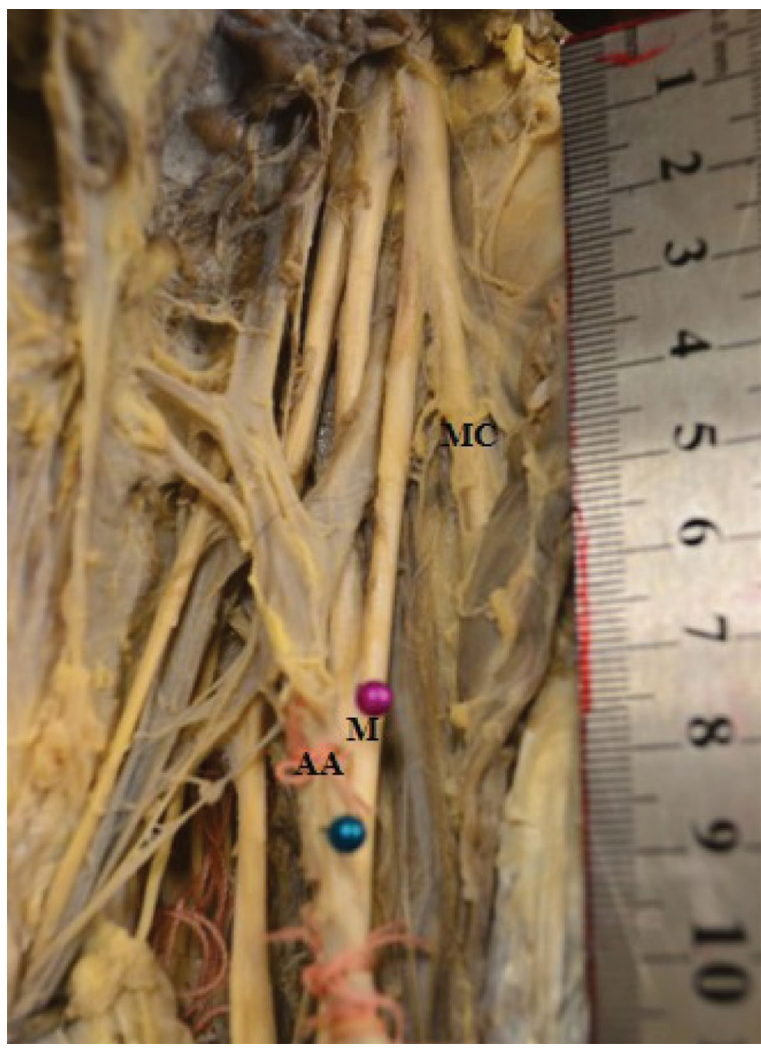

Figure 6. View of the median nerve running posterior to the axillary artery; AA — axillary artery; M — median nerve; MC — musculocutaneous nerve.

\section{Course of the median nerve in relation to the axillary artery}

In the present study, $13.6 \%$ (3/44) of the median nerves in the right upper limb run medial to the axillary artery and only one median nerve having the same variation was spotted on the left side (Fig. 5). Based on our observation, larger axillary artery may cause transposition of the median nerve to medial side. This study had similar finding as Budhiraja et al. [4] who found $6.12 \%$ (12/196) of upper limbs with the median nerve medial to the axillary artery, while Pandey and Shukla [14] with a study on 344 axillae found that in $2.3 \%$ (8/344) of cases the median nerve run medial to the axillary artery and Chitra [5] in her study reported a case where the median nerve run medial to the axillary artery bilaterally.

As for variation of the median nerve running posterior to the axillary artery, $13.6 \%$ were found on the left side and $4.5 \%$ on the right side (Fig. 6). This was in line with cases reported by Chitra [5] and Haviarova et al. [10]. Other median nerves run according to its normal course. 


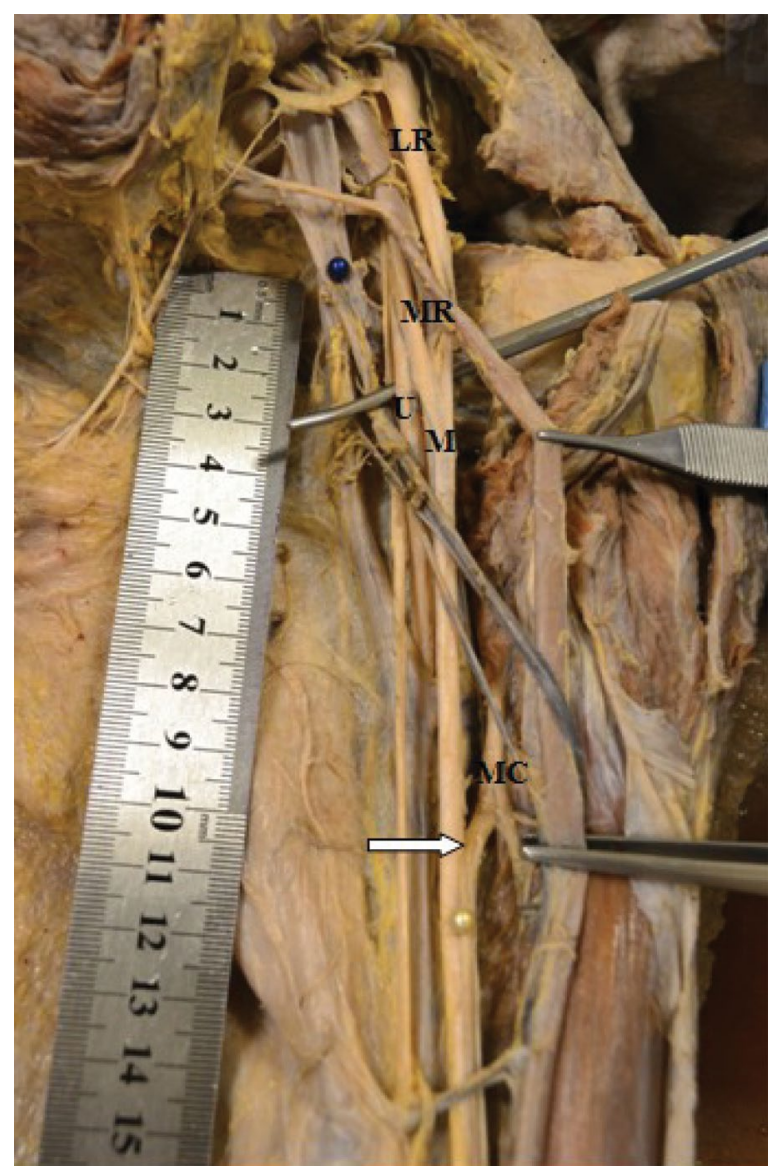

Figure 7. View of communicating branch between the median nerve and the musculocutaneous nerve. White arrow shows the communicating branch between the nerves; $L R$ - lateral root; $\mathrm{M}$ - median nerve; $\mathrm{MC}$ - musculocutaneous nerve; $\mathrm{MR}$ - medial root; U - ulnar nerve.

\section{Communication of the median nerve with other nerves}

In the present study, out of 44 upper limbs, $13.6 \%$ (3/44) showed variation in the communication between the median nerve and MC in the left limb (Fig. 4). In contrast, Kuar and Singla [12] found more of this variation in the right limb. In 1 of the 3 specimens, the MC joins the median nerve after supplying the biceps brachii muscle. Le Minor et al. [13] in their study classified communications between the median nerve and MC into five types while Choi et al. [6] classify them into another three different patterns which are: - pattern 1 - fusion of the nerve (14 arms, 19.2\%);

- pattern 2 - one connecting branch present between the nerves (53 arms, $72.6 \%$ );

- pattern 3 - two connecting branches present between the nerves ( 5 arms, $6.8 \%$ ).

In our study, 2 out of 3 upper limbs showed pat- tern 1 (Fig. 4) and 1 upper limb showed pattern 2 (Fig. 7). Francisco et al. [8] in his study of 50 upper limbs found that $10 \%$ (5/50) of the specimens showed communicating branch between the median nerve and MC. Beheiry [3] reported that among 60 arms studied, $5 \%(3 / 60)$ were found to have communicating branch between the median nerve and MC. This type of variations is most common, as reported by many authors, as MC and lateral root of the median nerve have common ventral branch of spinal nerves that emerges from cervical roots (C5, C6 and C7). However, our findings are quite different from other literature as we found more variations on three-root pattern of formation of the median nerve compared to communication with MC. Two out of 44 upper limbs showed type V of Le Minor's [13] classification, in which there were absent of MC (no communication with $\mathrm{MC}$ ) and thus, all the flexor muscles of arm were supplied by the median nerve. Besides that, we found $4.5 \%(1 / 44)$ of upper limbs on the right side showed communication between the median nerve and the ulnar nerve at the union of lateral and medial roots of the median nerve (Fig. 5). This is in line with a study performed by Felippe et al. [7] where 10\% (3/30) of upper limbs had Martin-Gruber anastomosis, which was one of the types of classification of communication between the median nerve and the ulnar nerve.

\section{Association of anatomical variations of the median nerve with the side of upper limb}

In the present study, more variations were found in the left upper limb; however, each variation showed no significant association with the side of upper limb, as the $p$ value obtained was more than 0.05 . Small sample size in this study may be the contribution factor for the result. There was no study reported in the literature on association of variations of the median nerve with the side of upper limb. There were two articles reporting more variations formed in the right upper limb, specifically for communication of the median nerve with MC, which is contradictory to our findings.

\section{CONCLUSIONS}

There is no consistency between variations of the median nerve with the side of upper limb; however, the knowledge on median nerve variations is essential to medical practitioners in dealing with surgery around axilla in order to prevent post-operative complications. It also helps in diagnosing patient with 
peripheral neuropathies and to differentiate partial or total traumatic injuries [7].

\section{Recommendation}

For any further study on anatomical variation of the median nerve, we suggest to include more than 50 upper limbs or use a bigger sample size, which might help in studying association between variations and the side of limbs. Besides, association between variations and gender can also be studied but the gender distribution should be taken into consideration and to make it almost equal although a few scholars have said that gender has no effect on the variations occurred.

\section{Acknowledgements}

The research was funded from 04-01-11-1162RU. We thank the reviewer for their constructive comments.

\section{REFERENCES}

1. Ahmed Khanfour A. Human anatomy upper limb. University of Alexandria, Anatomy Department, Egypt, 2009.

2. Badawoud MHM. A study on the anatomical variations of median nerve formation. Bahrain Med Bull. 2003; 25(4): 169-171.

3. Beheiry EE. Anatomical variation of the median nerve distribution and communication in the arm. Folia Morphol. 2004; 63 (3): 313-318, indexed in Pubmed: 15478107.

4. Budhiraja V, Rastogi R, Asthana AK. Anatomical variation of median nerve formation: embryological and clinical correlation, J Morphol Sci. 2011; 28: 283-286.

5. Chitra R. Multiple bilateral neuroanatomical variations of the nerves of the arm. Neuroanatomy. 2007; 6: 43-45.
6. Choi D, Rodríguez-Niedenführ M, Vázquez T, et al. Patterns of connections between the musculocutaneous and median nerves in the axilla and arm. Clin Anat. 2002; 15(1): 11-17, doi: 10.1002/ca.1085, indexed in Pubmed: 11835538.

7. Felippe MM, Telles FL, Soares ACL, et al. Anastomosis between median nerve and ulnar nerve in forearm. J Morphol Sci. 2012; 29: 23-26.

8. Francisco PR, Ana TSL, Ana TFB, et al. Study of the anatomical variations of the median nerve in human foetuses. Ann Res Rev Biol. 2014; 4: 2347-2356.

9. Frank NH. Atlas of human anatomy. 5th Ed. Elsevier Inc., Philadelphia, PA, 2011.

10. Haviarova Z, El Falougy HAK, Killingerova A. Atypical course of the median nerve. Bratisl Lek Listy. 2001; 102(8): 372-373.

11. Johnson D, Ellis H. Gray's anatomy: the anatomical basis for clinical practice. 39th Ed. Elsevier Churchill Livingstone, Philadelphia, PA, 2005.

12. Kaur N, Singla RK. Different types of communications between musculocutaneous nerve and median nerve: a cadaveric study in North Indian population. CIB Tech J Surg. 2013; 2(1): 21-28.

13. Le Minor JM. [A rare variation of the median and musculocutaneous nerves in man]. Arch Anat Histol Embryol. 1990; 73: 33-42, doi: 10.5580/2429, indexed in Pubmed: 1669679.

14. Pandey SK, Shukla VK. Anatomical variations of the cords of brachial plexus and the median nerve. Clin Anat. 2007; 20(2): 150-156, doi:10.1002/ca.20365, indexed in Pubmed: 16795062.

15. Richard S. Clinical anatomy by regions. 9th Ed. Lippincott Williams and Wilkins, Philadelphia, PA, 2012.

16. Romanes GJ. Cunningham's manual of practical anatomy. Vol. 1: Upper and lower limbs. 15th Ed. Oxford University Press, New York, US, 1986. 